\title{
Sex differences in counting and timing
}

\section{Christina L. Williams}

Department of Psychology and Neuroscience, Duke University, Durham, NC, USA

*Correspondence: williams@psych.duke.edu

It is generally agreed that there are significant and reliable sex differences in human cognition that can be revealed using laboratory based tasks (reviewed by Kimura, 1996; Loring-Meier and Halpern, 1999; Weiss et al., 2003). Animal models have shown that for at least one type of cognitive process, visual-spatial navigation, these sex differences are organized by exposure to gonadal steroids early in life (Williams et al., 1990; Williams and Meck, 1991, 1993) and are modulated by exposure to activational estrogens after puberty (Rapp et al., 2003; Sandstrom and Williams, 2004) as well as androgens (Bimonte-Nelson et al., 2003). Moreover, hormonally induced alterations in the hippocampus, and in the basal forebrain cholinergic projections to the hippocampus (Gould et al., 1991; Ragbetli et al., 2002; Berger-Sweeney, 2003; Veng et al., 2003; Gibbs, 2010) appear to be the neural mechanisms underlying these sex differences in spatial cognition.

Interestingly, there are a number of studies that suggest that men outperform women on tests of temporal discrimination and reproduction when the interval being timed is short, in the milliseconds to seconds range (Roeckelein, 1972; Strang et al., 1973; Rammsayer and Lustnauer, 1989; Wittmann and Szelag, 2003). It is less clear whether there are sex differences in the perception or production of longer intervals (seconds to minutes - see Friedman, 1977, but also see Block et al., 2000). These data suggest that there may be hormonally organized or activated differences in interval timing, a fundamental property of brain that is important for many behaviors (e.g., motor control, optimal foraging, spatial navigation, and higher-level cognition). To date, relatively little work has been done to examine possible underlying neuroendocrine development and modulation of interval timing. An examination of the neural and neuroendocrine underpinning of timing and time perception is particularly important because there are well known sex differences in the expression of developmental disabilities in learning and cognition (e.g., autism), as well as psychiatric illness (e.g., depression and schizophrenia) and neurodegenerative disease (e.g., Alzheimer's and Parkinson's disease).

Meck and colleagues (Meck and Church, 1983; Meck et al., 1985) developed a modecontrol model of temporal integration in which the same analog magnitude estimation system is used in different modes of pulse accumulation for both timing (run mode) and counting (event mode). In such a system, a count is equivalent to the amount of time that the accumulation process is active during the enumeration of the event. As a result, the final accumulation of counts in the event mode is functionally equivalent to the final accumulation of pulses during the run mode used for the timing of signal durations. Consequently, if counting and timing are considered basic building blocks for symbolic cognition (Cordes and Gelman, 2005; Cordes et al., 2007; Lustig, 2011), and if the temporal integration processes common to both abilities would be affected by neuroendocrine mechanisms, then one might be able to use deficits in temporal integration as early predictors of these disorders (see Allman, 2011; Allman and Meck, 2011; Allman et al., 2011; Falter and Noreika, 2011).

These findings raise several interesting questions. First, what is the extent of sex differences in temporal integration as related to timing and counting? Are sex differences in temporal integration seen only at short (small), millisecond intervals (counts) or across all temporal intervals (counts) as discussed by Buhusi and Cordes (2011)? Is the smallest unit of temporal integration (e.g., quantal unit) similar in male and female rats? While the behavioral data from male rats using signal durations over $2 \mathrm{~s}$ suggest that time and number are represented in the same fashion (Meck, 1997), similar procedures suggest differences between counting and timing in male rats when using intervals in the milliseconds range (Clarke et al., 1996) as well as differences between counting and timing in female rats (Breukelaar and Dalrymple-Alford, 1998).
A second issue is whether sex differences in timing and counting are modulated by organizational and activational effects of gonadal steroids? To date only a few studies have evaluated the effect of estradiol on timing and counting in adult female rats. Ross and Santi (2000) found that systemic administration of estradiol for 2 weeks impaired the ability of ovarectomized rats to use both time and number as discriminative stimuli. Two more recent studies have reported an increase in clock speed following the administration of estradiol to ovariectomized females (Sandstrom, 2007), but not to castrated males (Pleil et al., 2011), suggesting a sex difference in responsiveness to estradiol replacement. There is also some evidence that organizational actions of gonadal hormones may modify clock speed of adult rats (Pleil et al., 2011).A third unresolved issue is the determination of the neural representation of time and number in males and females. Current data indicate that cortico-striatal circuits, as well as dopaminergic afferents from the substantia nigra pars compacta, play a central role in interval timing (Harrington et al., 1998; Harrington and Haaland, 1999; Matell and Meck, 2000, 2004; Matell et al., 2003; Coull et al., 2011) and these circuits and their response to estrogen and dopaminergic agonists are sexually dimorphic (e.g., Becker, 1990, 1999; Bazzett and Becker, 1994; Xiao and Becker, 1994). In fact, the striatum is sexually dimorphic even during embryonic development, when the striata of females are more densely packed with dopamine axons and the GABAergic neurons that form striatal synapses than those of males (Ovtscharoff et al., 1992). To date most studies of the neural representation of time and number have used male subjects. Male rats with lesions of the dorsal striatum or substantia nigra pars compacta behave as though they have a severely impaired perception of time (Meck, 2006a,b). Dopaminergic drug administration either systemically (Meck, 1996, 2007; Cheng et al., 2007a,b,c) or intrastriatally (Neil and Herndon, 1978) alters the speed of interval timing processes. Moreover, male 
Parkinson's disease patients show deficits in reproducing durations when they are off of their dopaminergic medications (Malapani et al., 1998, 2002; Jahanshahi et al., 2010; Jones and Jahanshahi, 2011; Jones et al., 2011). Brain imaging studies in humans show the cortex and striatum are activated during timing tasks (Rao et al., 1997, 2001; Harrington et al., 1998; Hinton and Meck, 2004; Meck and Malapani, 2004; Meck et al., 2008; Allman and Meck, 2011; Coull et al., 2011). To date, no studies have compared neural activations during timing and counting tasks in males versus females.

Male-female differences have also been reported in the likelihood temporal information versus number information are used to solve discriminations. For example, when durations are larger than $2 \mathrm{~s}$ male rats readily and equally use both time and number to solve discrimination tasks (Meck and Church, 1983) while females preferentially use temporal cues over counting (Breukelaar and Dalrymple-Alford, 1998). Possible sex differences between temporal integration and numerical ability using durations in the order of hundreds of milliseconds remain to be investigated. The procedure that has been used to collect these data is the bisection procedure (Church and Deluty, 1977; Meck, 1983) and the specific variant of this procedure used to study counting and timing was developed by Meck and Church (1983) and has several features that make it ideally suited for these sex differences studies. The bisection procedures can be used to study counting and timing simultaneously (Breukelaar and Dalrymple-Alford, 1998; Paule et al., 1999), in a variety of species (rat: Meck and Church, 1983; Pleil et al., 2011; mouse: Penney et al., 2008; monkey: Merritt et al., 2010; human: Allan and Gibbon, 1991; Roitman et al., 2007) and across developmental stages (children: Droit-Volet and Meck, 2007; Droit-Volet et al., 2007; Lustig and Meck, 2011; aged adult: Lustig and Meck, 2001, 2011). As well, these procedures have the advantage of being able to dissociate timing at the short (millisecond to second) and long (seconds to minutes) durations as demonstrated by Breukelaar and Dalrymple-Alford (1998) and Melgire et al. (2005). Briefly, male and female rats can be trained to discriminate between four standard stimuli (sequences of on/off auditory events) which are either "time-relevant" or "number-relevant"; the "number-relevant" standard stimuli have a total duration of $4.0 \mathrm{~s}$ with either two or eight sound-on events, whereas the "timerelevant" standard stimuli have a total duration of 2.0 or $8.0 \mathrm{~s}$ with the total number of events held constant at four. After the discrimination is acquired, the four periodic standards are pseudorandomly mixed with probe (test) signals with variable duration (3.0, 4.0, 5.0, and 6.0 s) but constant number of events, four, and probe signals of constant duration (4.0 s) consisting of either 3, 4, 5, and 6 events (see Cordes et al., 2007). By using continuous or segmented stimuli in this procedure it is also possible to compute the equivalent time interval corresponding to one increment in counting, also known as "quantal unit" (Meck et al., 1985). The quantal unit has been show to be about $200 \mathrm{~ms}$ in male rats (Meck and Church, 1983) and humans (Whalen et al., 1999). As yet, separate quantal units for males and females tested in the same procedures remain to be determined.

\section{SEXUAL DIFFERENTIATION OF TIMING AND COUNTING}

As has been suggested recently (McCarthy and Arnold, 2011), there are a number of ways that sex differences in timing and counting might develop. The classic model (Phoenix et al., 1959) is that adult brain and behavior become sexually differentiated or organized during early development by gonadal hormones, which are released at high levels by male but not female fetuses. Thus, as a first step in exploring the underlying neuroendocrine basis of sex differences in timing and counting the early hormone environment of males and female can be manipulated and their adult behavior examine. This comparison allows for the determination of whether gonadal steroid exposure soon after birth hormonally organizes sex differences in timing/counting. To date, no study has manipulated hormones early in development and examined the consequences for both adult counting and timing, although as mentioned previously, clock speed appears to be organized by early gonadal hormones (Pleil et al., 2011).

It is also possible that sex differences in counting and timing might emerge because of sex differences in the effects of circulating estrogens in the adult female versus testosterone in the male. While this potential sex difference has never been explored, one study has evaluated the effect of estradiol on timing and counting in females (Ross and Santi, 2000) and revealed that low dose exposure to estradiol in females decreases both timing (in the 2-8 s range) and counting accuracy, but does not dissociate performance on timing and counting tasks. However, this study did not study male rats, and did not examine timing in the millisecond range. Future work should manipulate hormone exposure both developmentally and in adulthood in both males, and females across several cycles and compare the accuracy and precision of their timing and counting performance (see Pleil et al., 2011).

Recent evidence suggests that some sexually dimorphic pathways and behavior emerge because of direct genetic sex differences, rather than a cascade of hormonal events that stem from male-female genetic differences. For example, only males express the Sry gene, which is known to cause the differentiation of the male testes. Interestingly, Sry is also expressed in dopaminergic neurons in the substantia nigra that project to the striatum and have direct male-specific effects (Dewing et al., 2006). When Sry expression is reduced in adult rats, the expression of tyrosine hydroxylase in the substantia nigra and striatum are reduced and motor performance declines. Thus it is possible that direct, sex-specific effects of a sex chromosome gene may cause sex differences in the neural pathways underlying counting and timing. This possibility also remains unexplored.

\section{THE NEURAL REPRESENTATION OF TIME AND NUMBER}

Future studies should explore the representation of time and number by a network of neural substrates (including the basal ganglia, frontal cortex, and parietal cortex) in males and females using ensemble recordings at multiple sites (Vodolazhskaya and Beier, 2002; Varga et al., 2010; Coull et al., 2011). We hypothesize that the same neural substrates are involved in processing both temporal and numerical information, but that sexual dimorphisms in the neural substrates in temporal processing underlie differences in temporal integration and synchronization of the timing pattern as well as learning and memory for time in males and females (see Cheng et al., 2008). 


\section{REFERENCES}

Allan, L. G., and Gibbon, J. (1991). Human bisection at the geometric mean. Learn. Motiv. 22, 39-58.

Allman, M. J. (2011). Deficits in temporal processing associated with autistic disorder. Front. Integr. Neurosci. 5:2. doi: 10.3389/fnint.2011.00002

Allman, M. J., and Meck, W.H. (2011). Pathophysiological distortions in time perception and timed performance. Brain (in press). doi: 10.1093/brain/awr21

Allman, M. J., Pelphrey, K. A., and Meck, W. H. (2011). Developmental neuroscience of time and number: implications for autism and other neurodevelopmental disabilities. Front. Integr. Neurosci. (in press).

Bazzett, T. J., and Becker, J. B. (1994). Sex differences in the rapid and acute effects of estrogen on striatal D2 dopamine receptorbinding. Brain Res. 637, 163-172.

Becker, J. B. (1990). Direct effect of $17 \beta$-estradiol on striatum: sex differences in dopamine release. Synapse 5, 157-164.

Becker, J. B. (1999). Gender differences in dopaminergicf unction in striatum and nucleus accumbens. Pharmacol. Biochem. Behav. 64, 803-812.

Berger-Sweeney, J. (2003). The cholinergic basal forebrain system during development and its influence on cognitive processes: important questions and potential answers. Neurosci. Biobehav. Rev. 27, 401-411.

Bimonte-Nelson, H. A., Singleton, R. S., Nelson, M. E., Eckman, C. B., Barber, J., Scott, T. Y., and Granholm, A.-C. E. (2003). Testosterone, but not nonaromatizable dihydrotestosterone, improves working memory and alters nerve growth factor levels in aged male rats. Exp. Neurol. 181, 301-312.

Block, R. A., Hancock, P. A., and Zakay, D. (2000). Sex differences in duration judgments: a meta-analytic review. Mem. Cognit. 28, 1333-1346.

Breukelaar, J. W. C., and Dalrymple-Alford, J. C. (1998). Timing ability and numerical competence in rats. $J$. Exp. Psychol. Anim. Behav. Process. 24, 84-97.

Buhusi, C. V., and Cordes, S. (2011). Time and number: the privileged status of small values in the brain. Front. Integr. Neurosci. 5:67. doi: 10.3389/fnint.2011.00067

Buhusi, C. V., and Meck, W. H. (2005). What makes us tick? Functional and neural mechanisms of interval timing. Nat. Rev. Neurosci. 6, 755-765.

Cheng, R. K., Ali, Y. M., and Meck, W. H. (2007a). Ketamine "unlocks" the reduced clock-speed effect of cocaine following extended training: evidence for dopamine-glutamate interactions in timing and time perception. Neurobiol. Learn. Mem. 88, 149-159.

Cheng, R. K., Etchegaray, M., and Meck, W. H. (2007b). Impairments in timing, temporal memory, and reversal learning linked to neurotoxic regimens of methamphetamine intoxication. Brain Res. 1186, 255-266.

Cheng, R. K., Hakak, O. L., and Meck, W. H. (2007c). Habit formation and the loss of control of an internal clock: inverse relationship between the level of baseline training and the clock-speed enhancing effects of methamphetamine. Psychopharmacology (Berl.) 193, 351-362.

Cheng, R. K., MacDonald, C. J., Williams, C. L., and Meck, W.H. (2008). Prenatal choline supplementation alters the timing, emotion, and memory performance (TEMP) of adult male and female rats as indexed by differential reinforcement of low-rate schedule behavior. Learn. Mem. 15, 153-162.

Church, R. M., and Deluty, M. Z. (1977). Bisection of temporal intervals. J. Exp. Psychol. Anim. Behav. Process. 3, 216-228.
Clarke, S., Ivry, R., Grinband, J., Roberts, S., and Shimizu, N. (1996). "Exploring the domain of cerebellar timing," in Time, Internal Clocks and Movement, eds M.A. Pastor and J.Artieda (Amsterdam: Elsevier), 257-280. Cordes, S., and Gelman, R. (2005). “The young numerical mind: when does it count?" in Handbook of Mathematical Cognition, ed. J. Campbell (New York: Psychology Press), 127-142.

Cordes, S., Williams, C. L., and Meck, W. H. (2007). Common representations of abstract quantities. Curr. Dir. Psychol. Sci.16, 156-161.

Coull, J. T., Cheng, R. K., and Meck, W. H. (2011). Neuroanatomical and neurochemical substrates of timing. Neuropsychopharmacology 36, 3-25.

Dewing, P., Chiang, C. W., Sinchak, K., Sim, H., Fernagut, P. O., Kelly, S., Chesselet, M. F., Micevych, P. E., Albrecht, K. H., Harley, V. R., and Vilain, E. (2006). Direct regulation of adult brain function by the malespecific factor SRY. Curr. Biol. 16, 415-420.

Droit-Volet, S., and Meck, W. H. (2007). How emotions colour our perception of time. Trends Cogn. Sci. (Regul. Ed.) 11, 504-513.

Droit-Volet, S., Meck, W. H., and Penney, T. B. (2007) Sensory modality and time perception in children and adults. Behav. Processes 74, 244-250.

Falter, C. M., and Noreika, V. (2011). Interval timing deficits and abnormal cognitive development. Front. Integr. Neurosci. 5:26. doi: 10.3389/fnint.2011.00026

Friedman, E. R. (1977). Judgments of time intervals by young children. Percept. Mot. Skills 45, 715-720.

Gibbs, R.B.(2010).Estrogen therapy and cognition: a review of the cholinergic hypothesis. Endocr. Rev. 31, 224-253.

Gould, E., Woolley, C. S., and McEwen, B. S. (1991). The hippocampal formation: morphological changes induced by thyroid, gonadal and adrenal hormones. Psychoneuroendocrinology 116, 67-84.

Harrington, D. L., and Haaland, K. Y. (1999). Neural underpinnings of temporal processing: a review of focal lesion, pharmacological, and functional imaging research. Rev. Neurosci. 10, 91-116.

Harrington, D. L., Haaland, K. Y., and Hermanowicz, N. (1998). Temporal processing in the basal ganglia. Neuropsychology 12, 3-12.

Hinton, S. C., and Meck, W. H. (2004). Frontal-striatal circuitry activated by human peak-interval timing in the supra-seconds range. Cogn. Brain Res. 21, 171-182.

Jahanshahi, M., Jones, C. R., Zijlmans, J., Katzenschlager, R., Lee, L., Quinn, N., Frith, C. D., and Lees, A. J. (2010). Dopaminergic modulation of striato-frontal connectivity during motor timing in Parkinson's disease. Brain 133, 727-745.

Jones, C. R., Claassen, D., Yu, M., Spies, J. R., Malone, T., Dirnberger, G., Jahanshahi, M., and Kubovy, M. (2011). Modelling accuracy and variability of motor timing in treated and untreated Parkinson's disease and healthy controls. Front. Integr. Neurosci. 5:81. doi: 10.3389/fnint.2011.00081

Jones, C. R. G., and Jahanshahi, M. (2011). Dopamine modulates striato-frontal functioning during temporal processing. Front. Integr. Neurosci. 5:70. doi: 10.3389/fnint.2011.00070

Kimura, D. (1996). Sex, sexual orientation and sex hormones influence human cognitive function. Curr. Opin. Neurobiol. 6, 259-263.

Loring-Meier, S., and Halpern, D. F. (1999). Sex differences in visuospatial working memory: components of cognitive processing. Psychon. Bull. Rev. 6, $464-471$.
Lustig, C. (2011). The neuroscience of time and number: untying the Gordian knot. Front. Integr. Neurosci. 5:47. doi: $10.3389 /$ fnint.2011.00047

Lustig, C., and Meck, W. H. (2001). Paying attention to time as one gets older. Psychol. Sci. 12, 478-484.

Lustig, C., and Meck, W. H. (2011). Modality differences in timing and temporal memory throughout the lifespan. Brain Cogn. 77, 298-303.

Malapani, C., Deweer, B., and Gibbon, J. (2002). Separating storage from retrieval dysfunction of temporal memory in Parkinson's disease. J. Cogn. Neurosci. 14, 311-322.

Malapani, C., Rakitin, B., Levy, R., Meck, W. H., Deweer, B., Dubois, B., and Gibbon, J. (1998). Coupled temporal memories in Parkinson's disease: a dopaminerelated dysfunction. J. Cogn. Neurosci. 10, 316-331.

Matell,M.S., and Meck, W.H. (2000). Neuropsychological mechanisms of interval timing behaviour. Bioessays 22, 94-103.

Matell, M. S., and Meck, W. H. (2004). Cortico-striatal circuits and interval timing: coincidence-detection of oscillatory processes. Cogn. Brain Res. 21, 139-170.

Matell, M. S., Meck, W. H., and Nicolelis, M. A. L. (2003). Interval timing and the encoding of signal duration by ensembles of cortical and striatal neurons. Behav. Neurosci.117, 760-773.

McCarthy, M.M., and Arnold,A.P.(2011). Reframing sexual differentiation of the brain. Nat. Neurosci. 14, 677-683.

Meck, W. H. (1983). Selective adjustment of the speed of internal clock and memory processes. J. Exp. Psychol. Anim. Behav. Process. 9, 171-201.

Meck, W. H. (1996). Neuropharmacology of timing and time perception. Cogn. Brain Res. 3, 227-242.

Meck, W. H. (1997). “Application of a mode-control model of temporal integration to counting and timing behaviour," in Time and behaviour: Psychological and neurobiological analyses, eds C. M. Bradshaw and E. Szabadi (New York: Elsevier), 133-184.

Meck, W.H. (2006a). Frontal cortex lesions eliminate the clock speed effect of dopaminergic drugs on interval timing. Brain Res. 1108, 157-167.

Meck, W.H. (2006b). Neuroanatomical localization of an internal clock: a functional link between mesolimbic, nigrostriatal, and mesocortical dopaminergic systems. Brain Res. 1109, 93-107.

Meck, W.H. (2007). Acute ethanol potentiates the clockspeed enhancing effects of nicotine on timing and temporal memory. Alcohol. Clin. Exp. Res. 31, 2106-2113.

Meck, W. H., and Church, R. M. (1983). A mode control model of counting and timing processes. J. Exp. Psychol. Anim. Behav. Process. 9, 320-334.

Meck, W. H., Church, R. M., and Gibbon, J. (1985). Temporal integration in duration and number discrimination. J. Exp. Psychol. Anim. Behav. Process. 11, 591-597.

Meck, W. H., and Malapani, C. (2004). Neuroimaging of interval timing. Cogn. Brain Res. 21, 133-137.

Meck, W. H., Penney, T. B., and Pouthas, V. (2008). Cortico-striatal representation of time in animals and humans. Curr. Opin. Neurobiol. 18, 145-152.

Melgire, M., Ragot, R., Samson, S., Penney, T. B., Meck, W. H., and Pouthas, V. (2005). Auditory/visual duration bisection in patients with left or right medial temporal lobe resection. Brain Cogn. 58, 119-124.

Merritt, D. J., Casasanto, D., and Brannon, E. M. (2010). Do monkeys think in metaphors? Representations of space and time in monkeys and humans. Cognition 117, 191-202. 
Neil, D. B., and Herndon, J. G. Jr. (1978). Anatomical specificity within rat striatum for the dopaminergic modulation of DRL responding and activity. Brain Res. 153, 529-538.

Ovtscharoff, W., Eusterschulte, B., Zie-necker, R., Reisert, I., and Pilgrim, C. (1992). Sex differences indensities of dopaminergic fibers and GABAergic neurons in the prenatal rat striatum. J. Comp. Neurol. 323, 299-304.

Paule, M. G., Meck, W. H., McMillan, D. E., McClure, G. Y. H., Bateson, M., Popke, E. J., Chelonis, J. J., and Hinton, S. C. (1999). The use of timing behaviors in animals and humans to detect drug and/or toxicant effect. Neurotoxicol. Teratol. 21, 491-502.

Penney, T. B., Gibbon, J., and Meck, W. H. (2008). Categorical scaling of duration bisection in pigeons (Columba livia), mice (Mus musculus), and humans (Homo sapiens). Psychol. Sci. 19, 1103-1109.

Phoenix, C. H., Goy, R. W., Gerall, A. A., and Young, W. C. (1959). Organizing action of prenatally administered testosterone propionate on the tissues mediating mating behavior in the female guinea pig. Endocrinology 65, 369-382.

Pleil, K. E., Cordes, S., Meck, W. H., and Williams, C. L. (2011). Rapid and acute effects of estrogen on time perception in male and female rats. Front. Integr. Neurosci. 5:63. doi: 10.3389/fnint.2011.00063

Ragbetli, M. C., Aydinlioglu, A., and Kaplan, S. (2002). Sex differences and right-left asymmetries in rat hippocampal components. Int. J. Neurosci. 112, 81-95.

Rammsayer, T., and Lustnauer, S. (1989). Sex differences in time perception. Percept. Mot. Skills 68, 195-198.

Rao, S. M., Harrington, D. L., Haaland, K. Y., Bobholz, J. A., Cox, R. W., and Binder, J. R. (1997). Distributed neural systems underlying the timing of movements. J. Neurosci. 17, 5528-5535.

Rao, S. M., Mayer, A. R., and Harrington, D. L. (2001). The evolution of brain activation during temporal processing. Nat. Neurosci. 4, 317-323.
Repp, P. R., Morrison, J. H., and Roberts, J. A. (2003). Cyclic estrogen replacement improves cognitive function in aged ovariectomized rhesus monkeys. J. Neurosci. 23, 5708-5714.

Roeckelein, J.E. (1972). Sex differences in time estimation. Percept. Mot. Skills 35, 859-862.

Roitman, J. D., Brannon, E. M., Andrews, J. R., and Platt, M. L. (2007). Nonverbal representation of time and number in adults. Acta Psychol. (Amst.) 124, 296-318.

Ross, L., and Santi, A. (2000). The effects of estrogen on temporal and numerical processing in ovariectomized female rats. Psychobiology 28, 394-405.

Sandstrom, N. J. (2007). Estradiol modulation of the speed of an internal clock. Behav. Neurosci. 121, 422-432.

Sandstrom, N. J., and Williams, C. L. (2004). Spatial memory retention is enhanced by acute and continuous estradiol replacement. Horm. Behav. 45, 128-135.

Strang, H. R., Rust, J. O., and Garrison, S. G. (1973). Sex differences in short-term time estimation. Percept. Mot. Skills 36, 1109-1110.

Varga, M.E., Pavlova, O. G., and Nosova, S. V. (2010). The counting function and its representation in the parietal cortex in humans and animals. Neurosci. Behav. Physiol. 40, 185-196.

Veng, L. M., Granholm, A.-C., and Rose, G. M. (2003). Age-related sex differences in spatial learning and basal forebrain cholinergic neurons in F344 rats. Physiol. Behav. 80, 27-36.

Vodolazhskaya, M. G., and Beier,E.V.(2002).Assessment of disturbances in internal time counting and emotional behavior in rats with lesions to the striatum and hippocampus. Neurosci. Behav. Physiol. 32, 485-493.

Weiss, E. M., Kemmler, G., Deisenhammer, E. A., Fleischhacker, W. W., and Delazer, M. (2003). Sex differences in cognitive functions. Pers. Indiv. Differ. $35,863-875$.
Whalen, J., Gallistel, C. R., and Gelman, R. (1999). Nonverbal counting in humans: the psychophysics of number representation. Psychol. Sci. 10, 130-137.

Williams, C. L., Barnett, A. M., and Meck, W. H. (1990). Organizational effects of early gonadal secretions on sexual differentiation in spatial memory. Behav. Neurosci. 104, 84-97.

Williams, C. L., and Meck, W.H. (1991). Organizational effects of gonadal steroids on sexually dimorphic spatial ability. Psychoneuroendocrinology 16, 157-177.

Williams, C. L., and Meck, W.H. (1993). “Organizational effects of gonadal hormones induce qualitative differences in visuospatial navigation," in The Development of Sex Differences and Similarities in Behavior, eds M. Haug, R. E. Whalen, C. Aron, K. L. Olsen (Amsterdam: Kluwer Academic Publishers), 175-189.

Wittmann, M., and Szelag, E. (2003). Sex differences in perception of temporal order. Percept. Mot. Skills 96, 105-112.

Xiao, L., and Becker, J. B. (1994). Quantitative microdialysis determination of extracellular striatal dopamine concentration in male and female rats: effects of estrous cycle and gonadectomy. Neurosci. Lett. 180, 155-158.

Received: 02 December 2011; accepted: 02 December 2011; published online: 05 January 2012.

Citation: Williams CL (2012) Sex differences in counting and timing. Front. Integr. Neurosci. 5:88. doi: 10.3389/ fnint.2011.00088

Copyright (c) 2012 Williams. This is an open-access article distributed under the terms of the Creative Commons Attribution Non Commercial License, which permits non-commercial use, distribution, and reproduction in other forums, provided the original authors and source are credited. 